\title{
Oxidized Low-Density Lipoprotein Induces Inflammatory Responses in Cultured Human Mast Cells Via Toll-Like Receptor 4
}

\author{
Zhe Meng $^{\mathrm{a}}$ Chao Yan ${ }^{\mathrm{a}}$ Qian Deng ${ }^{\mathrm{b}}$ Xin Dong ${ }^{\mathrm{a}}$ Zong-Ming Duan ${ }^{\mathrm{a}}$ Deng-Feng Gao
} Xiao-Lin Niu ${ }^{\mathrm{a}}$

aDepartment of Cardiology, The Second Affiliated Hospital, Xi'an Jiaotong University School of Medicine, Xi'an, Shaanxi, China; 'Department of Urology, The Second Affiliated Hospital, Xi'an Jiaotong University School of Medicine, Xi'an, Shaanxi, China

\section{Key Words}

Oxidized low-density lipoprotein • Mast cells • Inflammatory responses • Toll-like receptor 4

\begin{abstract}
Background/Aims: Oxidized low-density lipoprotein (ox-LDL) is a powerful atherogen. Tolllike receptor 4 (TLR4) has a pathophysiological role in regulating inflammatory responses and atherosclerosis. Mast cells can infiltrate into the atheromatous plaque and secrete various pro-inflammatory cytokines, which significantly amplify the atherogenic processes and promote plaque vulnerability. Small interfering RNA (siRNA) is an effective method to silence the target genes. We evaluated whether ox-LDL-induced inflammation depended in part on the activation of TLR4-dependent signaling pathways in a cultured human mast cell line (HMC-1). Method: HMC-1 cells were cultured, and treated with ox-LDL, TLR4-specific siRNA, or inhibitors of phosphorylation of mitogen-activated protein kinase (MAPKs), and nuclear factor- $\mathrm{KB}$ (NF-KB), a critical mediator of inflammation. The expression of monocyte chemoattractant protein-1 (MCP-1), tumor necrosis factor- $\alpha$ (TNF- $\alpha$ ) and interleukin 6 (IL- 6 ) was measured subsequently. Results: Ox-LDL increased the expression of TLR4 and secretion of MCP-1, TNF- $\alpha$ and IL-6. Moreover, ox-LDL stimulated the translocation of NF- $K B$, from the cytoplasm to nucleus. Additionally, phosphorylation of MAPK was greatly increased. These ox-LDL-induced alterations were significantly attenuated by pretreatment with TLR4specific siRNA. Conclusion: Ox-LDL induced inflammatory responses in cultured HMC-1 cells including NF-KB nuclear translocation and phosphorylation of MAPKs, a process mediated in part by TLR4.
\end{abstract}




\section{Introduction}

Atherosclerosis is characterized by the accumulation of modified lipids and infiltration and activation of inflammatory cells, as well as fibrous elements, in the inner or middle layers of arteries. Since plaques are vulnerable to rupture, this may cause serious cardiovascular atherothrombotic disease [1-3]. Growing evidence reveals that a chronic inflammatory response contributes to atherogenesis and plaque disruption, and the innate immune response plays a critical role in the initiation of this process [3-6]. Monocyte chemoattractant protein-1 (MCP-1), tumor necrosis factor- $\alpha$ (TNF- $\alpha$ ) and interleukin 6 (IL-6) are pro-inflammatory cytokines that play an important role in the induction of the inflammatory cascade within atherosclerotic plaques, by recruiting monocytes or macrophages into the tunica and media intima of arteries walls, increasing the expression of other cytokines and adhesion molecules, and increasing the release of fibrinogen and inducing aggregation of platelets [7-9].

Oxidative stress is an important manifestation of the inflammatory responses during the atherogenesis. During the initiation of atherogenesis, low-density lipoprotein (LDL) is first entrapped in the intima. Subsequently, it is oxidized and is now referred to as oxidized low-density lipoprotein (ox-LDL), a potential linker between the immune response and atherogenesis $[10,11]$. Increasing evidence indicates that ox-LDL is a powerful pro-inflammatory and pro-atherogenic factor in all stages of atherosclerosis by inducing the expression of cytokines and chemokineses in macrophages, vascular smooth muscle cells (VSMCs) and endothelial cells [12]. Numerous clinical studies have indicated that serum levels of ox-LDL are an important predictor of the severity of acute coronary syndrome $[13,14]$.

Toll-like receptor 4 (TLR4), a critical key factor in regulating innate immune response, induces remarkable expression of pro-inflammatory and pro-atherogenic cytokines in macrophages, VSMCs and endothelial cells when activated by binding to its ligand [15-17]. While TLR4 was originally described as a pattern receptor that recognizes lipopolysaccharide (LPS), recently, endogenous ligands have been found that are powerful TLR4 activators; examples are ox-LDL, fibronectin and heat shock protein 60 [18]. Increased expression of TLR4 within lipid-rich atherosclerotic plaques in both human and animal models has been reported in the literature $[19,20]$. Almost all cell types implicated in atherosclerosis express the TLR4, and additionally, ox-LDL has been shown to course expression of TLR4 in macrophages and VSMCs [21]. Mast cells may play a role in amplifying atherogenic processes and promoting plaque vulnerability by secreting various cytokines and chemokines [22, 23]. Myeloid differentiation factor 88 (Myd88), an adaptor molecule, plays a critical role in the activity of the TLR4 signaling pathway [24]. The activation of NF- $\mathrm{BB}$ (p65), a downstream mediator in the TLR4 signaling cascade, induces expression of many pro-inflammatory cytokines, which contribute to atherosclerosis [25]. MAPKs, (ERK1/2, JNK1/2, and p38MAPK) are an important group downstream of TLR4-mediated Myd88-dependent signaling, which transmit and enhance the TLR4 signal [26]. However, whether ox-LDL can stimulate mast cells to increase their expression by a TLR4-dependent signaling pathway is unknown. Small interfering RNA (siRNA) is an effective tool for silencing a target gene, at the transcriptional, posttranscriptional, and/or translational level, by inducing degradation of target gene mRNA. Here, we used TLR4-specific siRNA to test the hypothesis that downregulation of TLR4-expression can inhibit ox-LDL-induced inflammation.

Here, we investigated whether ox-LDL can increase the expression of TLR4 in cultured mast cells, and whether this inflammatory response depends on TLR4 signaling using TLR4specific siRNA to test the hypothesis that downregulation of TLR4-expression can inhibit ox-LDL-induced inflammation.

\section{Materials and Methods}

\section{Reagents}

Rabbit polyclonal antibodies against TLR4, Myd88, NF-кB (P65), p38MAPK, phosphorylated-p38MAPK (p-p38MAPK), extracellular signal-regulated kinase 1/2 (ERK1/2), p-ERK1/2, c-Jun N-terninal kinase (JNK) 
and p-JNK were obtained from Santa Cruz Biotechnology (Santa Cruz, CA, USA). Fetal bovine serum (FBS), penicillin and streptomycin were purchased from Gibco BRL (Carlsbad, CA, USA). Anti-human tumor necrosis factor- $\alpha$ (TNF- $\alpha$ ), interleukin 6 (IL-6) and monocyte chemoattractant protein 1 (MCP-1) ELISA kits were obtained from R\&D Systems (Minneapolis, MN, USA). PDTC, SB203580, SP600125 and PD98059 were from Sigma Chemical Co. (Sigma, St. Louis, MO, USA).

\section{Cell culture}

A Human mast cell line (HMC-1) originally derived from a patient with mast cell leukemia and which is the only established cell line exhibiting a phenotype similar to that of human mast cells was used in our study [27]. HMC-1 cells were grown in Iscove's modified Dulbecco's medium supplemented with $10 \%$ fetal bovine serum, $1.2 \mathrm{mmol} / \mathrm{L}$ monothioglycerol, $2 \mathrm{mmol} / \mathrm{L}$ L-glutamine, $100 \mathrm{U} / \mathrm{mL}$ penicillin and $100 \mu \mathrm{g} / \mathrm{mL}$ streptomycin either in $25 \mathrm{~cm}^{2}$ tissue culture plates or in six-well tissue culture plates (Costar). Cells were grown at an incubator in $5 \% \mathrm{CO}_{2}$ and $95 \% \mathrm{O}_{2}$ at $37^{\circ} \mathrm{C}$.

\section{Isolation and oxidation of $L D L$}

Human LDL ( $\mathrm{d}=1.030-1.063 \mathrm{~g} / \mathrm{L})$ was isolated by density ultracentrifugation, at $5000 \mathrm{rpm} / \mathrm{min}$ for $22 \mathrm{~h}$, from EDTA-treated $(1 \mathrm{mg} / \mathrm{mL}$ ) plasma collected from normal lipidemic donors. The LDL supernatant was dialyzed against isotonic saline to remove EDTA. Oxidation of LDL was carried out by incubating LDL with $5 \mu \mathrm{mol} / \mathrm{L} \mathrm{CuSO}_{4}$ at $37{ }^{\circ} \mathrm{C}$ for $24 \mathrm{~h}$. The oxidation reaction was stopped by extensive dialysis against $0.01 \%$ EDTA phosphate-buffered saline and the dialysate was sterilized by filtration through a $0.22-\mathrm{mm}$ filter. The extent of oxidation of the LDL preparations was determined by measuring thiobarbituric acid reactive substance (TBARS) (PeroX-Oquant, Pierce, Rockford, IL). Another control LDL sample was processed in parallel, and however, without $\mathrm{CuSO}_{4}$ addition. The results showed that oxidized low-density lipoprotein (oxLDL) contained 15.47 TBARS/mg protein and LDL contained 1.62 TBARS/mg protein. Endotoxin contamination of all preparations was determined by the kinetic-turbidimetric Limulus amebocyte lysate assay (Sigma), which was performed by an independent laboratory. The results showed that the concentration of endotoxin was below the detection limit $(0.125$ endotoxin units $/ \mathrm{mL}$, corresponding to $\approx 0.01 \mathrm{ng} / \mathrm{mL}$ LPS).

\section{Enzyme-linked immunoassay for cytokines and chemokines}

HMC- 1 cells were seeded into 6 -well plates at $4 \times 10^{6} /$ well and incubated with LDL ( $50 \mu \mathrm{g} / \mathrm{mL}$ ) or oxLDL $(10,50,100 \mu \mathrm{g} / \mathrm{mL})$ for 3, 6, 12, $24 \mathrm{~h}$. Mast cells were transfected with siRNA as described below. After $24 \mathrm{~h}$, they were stimulated with ox-LDL $(10,50,100 \mu \mathrm{g} / \mathrm{mL})$ for $3,6,12,24 \mathrm{~h}$. Cells were pretreated with

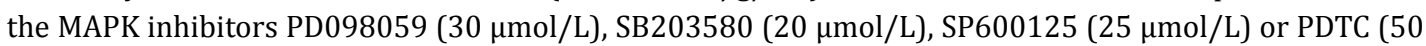
$\mu \mathrm{mol} / \mathrm{L}$ ) for $1 \mathrm{~h}$, and then stimulated with LDL or ox-LDL for another $24 \mathrm{~h}$. TNF- $\alpha$, IL-6 and MCP-1 levels in the supernatant were measured by ELISA according to the manufacturer's instruction.

\section{Small-Interfering RNA}

HMC- 1 cells $\left(5 \times 10^{6}\right)$ were cultured in 6 -well plates and grown to about $60 \%$ to $70 \%$ confluence, then transiently transfected with $100 \mathrm{pM}$ of TLR4 small interfering (siRNA) duplex oligonucleotides (on-TARGET plus SMART pool, Thermo Fisher Scientific, Rockford, IL) or non-target duplex oligonucleotides (on-TARGET plus siCONTROL, Thermo Fisher Scientific), as a negative control siRNA using TransLipid ${ }^{\mathrm{TM}}$ transfection agent (Transgen Biotech, Beijing, China) according to the manufacturer's instruction. After $24 \mathrm{~h}$, mRNA and protein levels of TLR4 were analyzed. Transfection rates of $50 \%$ to $60 \%$ were used for the other experiments.

\section{Immunohistochemistry of $H M C-1$ cells}

To examine the expression of TLR4 in ox-LDL-stimulated HMC-1, the cells were seeded into 6-well plates at $4 \times 10^{6} /$ well and incubated with LDL $(50 \mu \mathrm{g} / \mathrm{mL})$ or ox-LDL $(100 \mu \mathrm{g} / \mathrm{mL})$ for $24 \mathrm{~h}$. Subsequently, the cells were fixed with $4 \%$ formaldehyde-PBS for $15 \mathrm{~min}$ followed by a disruption of the cell membranes using $0.3 \%$ Triton-100-PBS, and nonspecific binding site were blocked by incubation with $10 \%$ goat serum for $20 \mathrm{~min}$. The cells were incubated with TLR4 antibody (1: 100) for $24 \mathrm{~h}$ at $4^{\circ} \mathrm{C}$, and then incubated with a secondary antibody conjugated with $\mathrm{Cy} 3$. The immunolabeled cells were visualized using a fluorescence confocal microscopy (Leica TCS SP2-AOB). 


\begin{tabular}{ll}
\hline Gene & Primer sequence \\
\hline TLR4 & 5'-TACAAAATCCCCGACAACCTCC-3' \\
& 5'-GCTGCCTAAATGCCTCAGGG-3' \\
Myd88 & 5'-ACAGGCACCAGCATACAC-3' \\
& 5'-TTGGGTCCTTTCCAGAGT-3' \\
IL-6 & 5'-CCAGCTATGAACTCCTTCTC-3' \\
& 5'-GCTTGTTCCTCACATCTCTC-3' \\
MCP-1 & 5'-GCTCAGCCAGATGCAAT -3' \\
& 5'-GCTTGTCCAGGTGGTCCATG -3' \\
TNF- $\alpha$ & 5'-ATGAGCACTGAAAGCATGATCC-3' \\
& 5'-GAGGGCTGATTAGAGAGAGGTC-3' \\
GAPDH & 5'-GAATTTGGCTACAGCAACAGGGTG-3' \\
& 5'-TCTCTTCCTCTTGTGCTCTTGCTG-3' \\
\hline
\end{tabular}

Table 1. Primers for real-time PCR

\section{Quantitative real-time PCR}

Total RNA was extracted using TransZol reagent (TransGen Biotech, Beijing). DNA was removed using DNA-free kit (Ambion, Austin TX, USA). The quality of total mRNA was checked by denaturing agarose gel electrophoresis containing 1.5\% formaldehyde. Total RNA concentration and purity were determined by using UV-Vis spectroscopy with the Bio-Rad SmartSpec 3000 system (Bio-Rad Hercules, CA, USA). cDNA was synthesized from $1 \mu \mathrm{g}$ total RNA in a $20 \mu \mathrm{L}$ reaction using oligo(dT)18 Primers and TransScript ${ }^{\mathrm{TM}}$ Reverse Transcriptase (TransGen Biotech, Beijing). Primers for human TLR4, Myd88, TNF- $\alpha$, MCP-1, IL-6 and $\beta$-actin were designed using a Beacon designer v4.0 (Premier Biosoft, USA) (see Table 1 for the sequences). GAPDH was used as endogenous control. mRNA levels of TLR4, Myd88, TNF- $\alpha$, MCP-1, IL-6, and GAPDH were measured by real-time PCR with the ABI PRISM 7000 sequence detection PCR system (Applied Biosystems, Foster City, CA, USA). A melting point dissociation curve was used to confirm that only a single PCR product was obtained. Results were expressed as fold difference relative to the level of GAPDH by the $2^{-\triangle \Delta C T}$ method. Serial 10-fold dilutions of cDNA were used to confirm near-theoretical efficiencies of the assay.

\section{Western blot assay}

Mast cell lysates of approximately $5 \times 10^{6}$ cells were prepared using $200 \mu \mathrm{L}$ ice-cold lysis buffer (pH 7.4) (50 mmol/L HEPES, 5 mmol/L EDTA, $100 \mathrm{mmol} / \mathrm{L} \mathrm{NaCl}, 1 \%$ Triton X-100, protease inhibitor cocktail; Roche, Mannheim, Germany) in the presence of phosphatase inhibitors (50 mmol/L sodium fluoride, $1 \mathrm{mmol} / \mathrm{L}$ sodium orthovanadate, $10 \mathrm{mmol} / \mathrm{L}$ sodium pyrophosphate, $1 \mathrm{nmol} / \mathrm{L}$ microcystin). The nuclear NF- $\mathrm{BB}$ (p65) protein was extracted using the Pierce NE-PER kit (Pierce, Rockford, IL, USA). A BCA protein assay kit was used to measure protein concentration. Samples underwent 10\% SDS-PAGE and were transferred onto a polyvinylidene difluoride membrane in a semi-dry system (Bio-Rad), which was blocked with $5 \%$ fat-free milk in TBST buffer (20 mmol/L Tris- $\mathrm{HCl}, 137 \mathrm{mmol} / \mathrm{L} \mathrm{NaCl}$ and $0.1 \%$ Tween 20 ), and incubated with primary antibodies against TLR4 (1:200), Myd88 (1:500), I $\mathrm{B} \alpha(1: 400), \mathrm{NF}-\kappa \mathrm{B}(\mathrm{p} 65)$ (1:200), p38 and p-p38MARK (both 1:500), ERK1/2, p-ERK1/2 (both 1:500), JNK, and p-JNK (both 1:200), respectively, in TBST buffer overnight, then washed and incubated with secondary antibodies for $90 \mathrm{~min}$. Optical density of the bands was scanned and quantified using a Gel-Pro Analyzer v4.0 (Media Cybernetics, L.P.). $\beta$-actin was used as endogenous control. Data were normalized to $\beta$-actin levels.

\section{Statistical analysis}

Results are expressed as means \pm S.E.M. of three experiments. Differences between groups were assessed by Student $t$ test and one- or two-way ANOVA, and then by post hoc Duncan multiple comparisons, with use of SPSS 17.0 (SPSS Inc., Chicago, IL, USA). A value of $P<0.05$ was considered statistically significant.

\section{Results}

Ox-LDL induced chemokine and cytokine expression in cultured HMC-1 cells

Mast cells express a number of inflammatory chemokines and cytokines after receiving various stimuli. We found increased expression of MCP-1, TNF- $\alpha$ and IL-6, after incubation with ox-LDL, all inflammatory mediators involved in the progression of atherosclerosis. The 
Fig. 1. Effect of oxidized low density lipoprotein (ox-LDL) on mRNA and protein levels of chemokine and cytokine in cultured HMC-1 cells. HMC-1 cells were incubated with ox-LDL (10, 50 and $100 \mu \mathrm{g} / \mathrm{mL}$ ) or native $\mathrm{LDL}(50 \mu \mathrm{g} / \mathrm{mL})$ for $3,6,12$ or $24 \mathrm{~h}$. (a) ELISA quantification of monocyte chemoattractant protein 1 (MCP-1), tumor necrosis factor $\alpha$ (TNF- $\alpha$ ) and interleukin 6 (IL-6). (b) HMC- 1 cells were incubated with oxLDL (10, 50 and $100 \mu \mathrm{g}$ / $\mathrm{mL}$ ) or native LDL (50 $\mu \mathrm{g} / \mathrm{mL}$ ) for $6 \mathrm{~h}$. Quantitative real-time PCR analysis of mRNA levels of MCP-1, TNF- $\alpha$ and IL6. Normalization was to GAPDH mRNA level. Data are mean \pm S.E.M. of three independent experiments. ${ }^{*} P<0.05$ vs control.

\section{a}
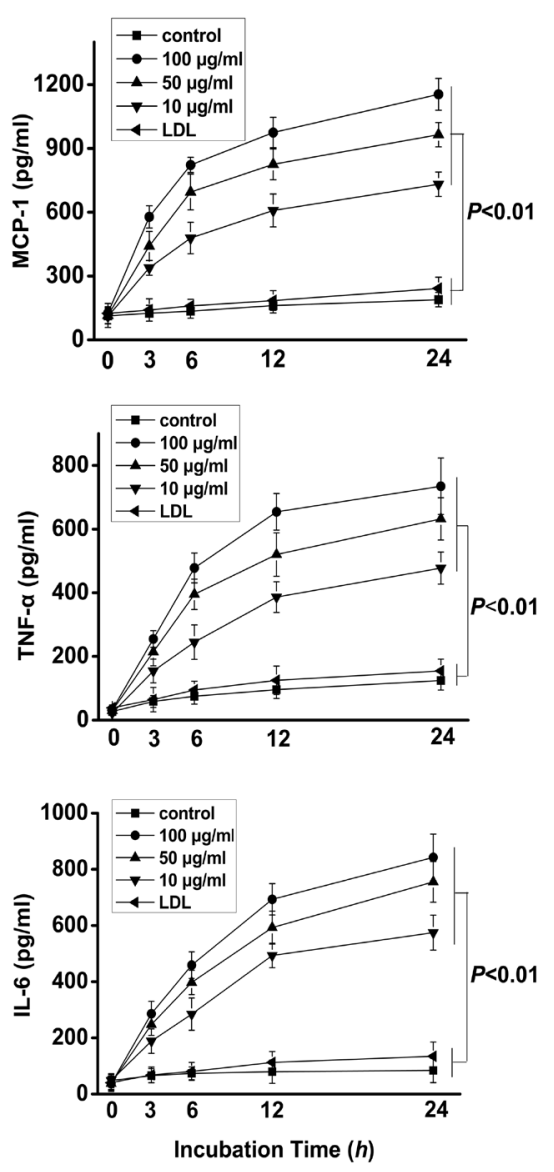

b
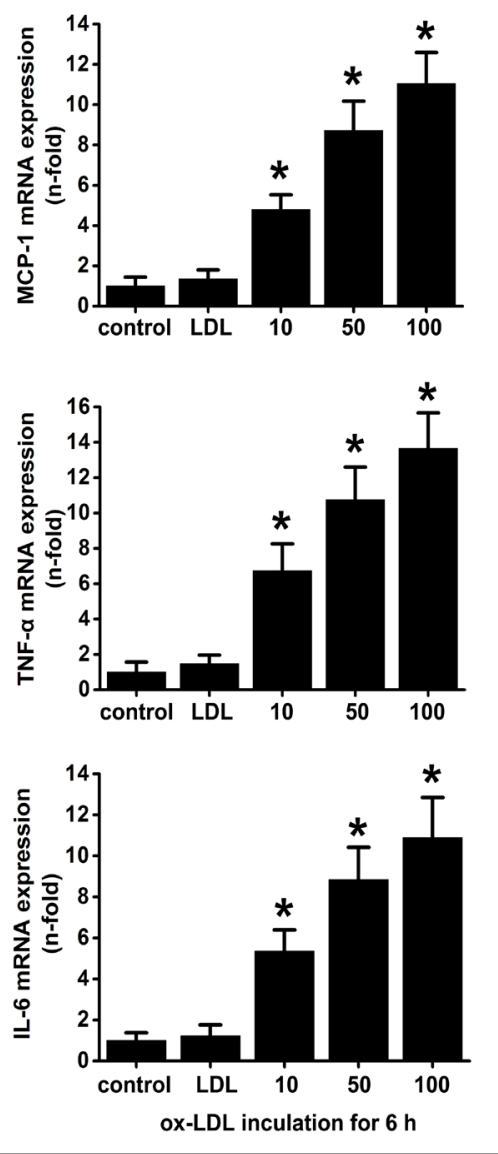

production of MCP-1, TNF- $\alpha$ and IL- 6 protein was significantly upregulated in a time and concentration dependent manner (Fig. 1a). Moreover, increasing amounts of ox-LDL dosedependently increased the mRNA levels of MCP-1, TNF- $\alpha$ and IL-6, after incubation with oxLDL $(10,50,100 \mu \mathrm{g} / \mathrm{mL}$ ) for $6 \mathrm{~h}$ (Fig. 1b). However, native LDL had no effect on the mRNA and protein levels of these factors.

Ox-LDL increased the expression of TLR4 in cultured HMC-1 cells

To investigate whether TLR4 is regulated by ox-LDL in cultured HMC-1 cells, cells were stimulated with different concentrations of ox-LDL for 6 or $24 \mathrm{~h}$. Real-time PCR and westernblot revealed that protein and mRNA levels of TLR4 were dose-dependently increased in HMC-1 cells (Fig. 2a and 2b). However, native LDL had no effect on the mRNA or protein levels of TLR4. The immunohistochemistry results also showed that ox-LDL increased TLR4 expression in VSMCs (Fig. 2c).

Effect of ox-LDL on the activation of Myd88, degradation of $I \kappa B \alpha$, and $N F-\kappa B$ in cultured HMC-1 cells

HMC- 1 cells were incubated with ox-LDL at different concentrations for 6 or $24 \mathrm{~h}$, followed by detection of NF- $\kappa B$ (p65) in cytosolic and nuclear fractions. The concentration of $\mathrm{I} \kappa \mathrm{B} \alpha$, a NF- $\kappa \mathrm{B}$ inhibitor, was also measured. Ox-LDL markedly increased protein and mRNA levels of Myd88 (Fig. 3a). Furthermore, ox-LDL increased the degradation of I $\kappa \alpha \alpha$ and induced nuclear translocation of NF- $\kappa B$ (p65) evidenced by increased nuclear NF- $\kappa B$ and decreased cytosolic NF- $\kappa$ B contents, compared to the control group (Fig. $3 \mathrm{~b}$ and $3 \mathrm{c}$ ). However, 
Fig. 2. Effect of ox-LDL on Tolllike receptor 4 (TLR4) level in cultured HMC-1 cells. (a) Quantitative real-time PCR analysis of mRNA levels of TLR4 in HMC-1 cells incubated with ox-LDL (10, 50 and $100 \mu \mathrm{g} / \mathrm{mL})$ or native LDL $(50 \mu \mathrm{g} / \mathrm{mL})$ for $6 \mathrm{~h}$. Normalization to GAPDH mRNA levels. (b) Western-blot analysis of TLR4 in HMC-1 cells incubated with ox-LDL $(10,50$ and $100 \mu \mathrm{g} / \mathrm{mL}$ ) or native LDL $(50 \mu \mathrm{g} / \mathrm{mL})$ for $24 \mathrm{~h}$. Gray levels were normalized against $\beta$-actin, and results were expressed as relative to control. Data are mean \pm S.E.M. of three independent experiments. ${ }^{*} P<0.05$ vs control. (c) Immunofluorescent analysis of TLR4 expression induced by ox-LDL $(100 \mu \mathrm{g} / \mathrm{mL})$ or LDL $(50 \mu \mathrm{g} /$ $\mathrm{mL}$ ) for $24 \mathrm{~h}$.

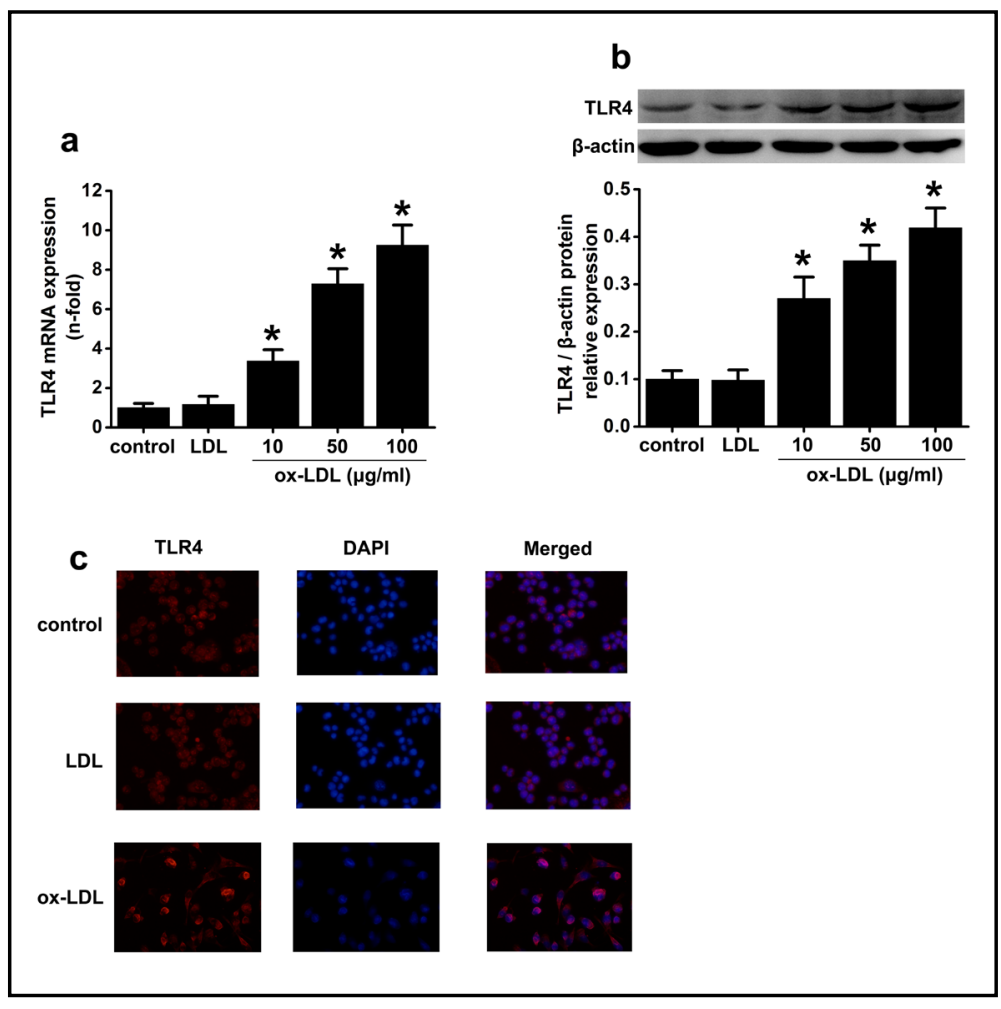

native LDL had no effect on the expression of Myd88, degradation of I $\kappa \mathrm{B} \alpha$, and translocation of NF- $\mathrm{B}$ (p65).

\section{Effect of ox-LDL on phosphorylation of ERK1/2, p38MAPK and JNK1/2 in cultured HMC-1} cells

Downstream in the Myd88-dependent TLR4 signaling pathway, the MAPKs ERK1/2, p38MAPK and JNK1/2 play important roles in the inflammatory response, accordingly, the effects of ox-LDL or native LDL on phosphorylation of MAPKs was investigated. HMC-1 cells were treated with ox-LDL or LDL at the concentration of 10,50 , and $100 \mu \mathrm{g} / \mathrm{mL}$ for $30 \mathrm{~min}$. Phosphorylation of MAPKs was measured by western-blot. Ox-LDL dose-dependently increased the phosphorylation of ERK1/2, p38MARK and JNK1/2 in HCM-1 cells. However, native LDL had no effect on the phosphorylation of MAPKs (Fig. 4a, b, and c).

Involvement of TLR4 in ox-LDL induced inflammation in cultured HMC-1 cells

To observe whether TLR4 is involved in the upregulation of cytokines in cultured HMC1 cells after ox-LDL stimulation, we pretreated cells with TLR4 siRNA or negative control siRNA, followed by an incubation with ox-LDL $(100 \mu \mathrm{g} / \mathrm{mL})$ for $6 \mathrm{~h}$ or $24 \mathrm{~h}$. The protein and mRNA levels of TLR4 were downregulated by TLR4-specific siRNA with or without ox-LDL (Fig 5a). TLR4-specific siRNA significantly inhibited ox-LDL-induced upregulation of mRNA and protein levels of inflammatory mediators in cultured HMC-1 cells (Fig. $5 b$ and c). Thus, TLR4 might play an important role in regulating MCP-1, TNF- $\alpha$ and IL-6 production in oxLDL-stimulated HMCs.

\section{Effect of inhibitors on the production of inflammatory mediators}

To explore the functions of NF- $\mathrm{BB}$ and MAPKs pathways in ox-LDL-stimulated HMC-1 cells, we examined the effect of NF- $\mathrm{BB}$ and MAPKs inhibition on the production of inflammatory mediators. As seen previously, MCP-1, TNF- $\beta$ and IL- 6 levels were increased in ox-LDLstimulated HMC-1 cells as compared to controls (Fig. $6 \mathrm{a}$ and b). HMC-1 cells were pretreated 
Fig. 3. Effect of ox-LDL on Myd88 level, NF- $\kappa \mathrm{B}$ activation, and $\mathrm{I} \kappa \mathrm{B} \alpha$ degradation in HMC-1 cells. (a) Western-blot analysis of Myd88 protein expression in HMC-1 cells incubated with ox-LDL $(10,50$ and $100 \mu \mathrm{g} / \mathrm{mL}$ ) or native LDL (50 $\mu \mathrm{g}$ / $\mathrm{mL}$ ) for $24 \mathrm{~h}$ and quantitative realtime PCR detection of Myd88 mRNA expression in HMC-1 cells incubated with ox-LDL (10, 50 and $100 \mu \mathrm{g} /$ $\mathrm{mL})$ or native LDL $(50 \mu \mathrm{g} / \mathrm{mL})$ for 6 h. Normalization to GAPDH mRNA level. (b) The expression of nuclear NF- $\kappa \mathrm{B}$ (p65) and cytosolic NF- $\kappa \mathrm{B}$ (p65) was measured by westernblot assay, after HMC-1 cells were incubated with ox-LDL (10, 50 and $100 \mu \mathrm{g} / \mathrm{mL}$ ) or native LDL (50 $\mu \mathrm{g}$ / $\mathrm{mL}$ ) for $24 \mathrm{~h}$. (c) The degradation of I $\kappa \alpha$ were analyzed by western-blot, in HMC-1 cells incubated with ox-LDL $(10,50$ and $100 \mu \mathrm{g} / \mathrm{mL})$ or native LDL $(50 \mu \mathrm{g} / \mathrm{mL})$ for $24 \mathrm{~h}$. Histone was used to be the internal control to reflect the expression of nuclear NF- $\kappa B$ (p65), $\beta$-actin was used to as internal control in other results. Gray levels were normalized against histone or $\beta$-actin, respectively, and results were expressed as relative to control. Data are mean \pm S.E.M. of three independent experiments. ${ }^{*} P<0.05$ vs control.

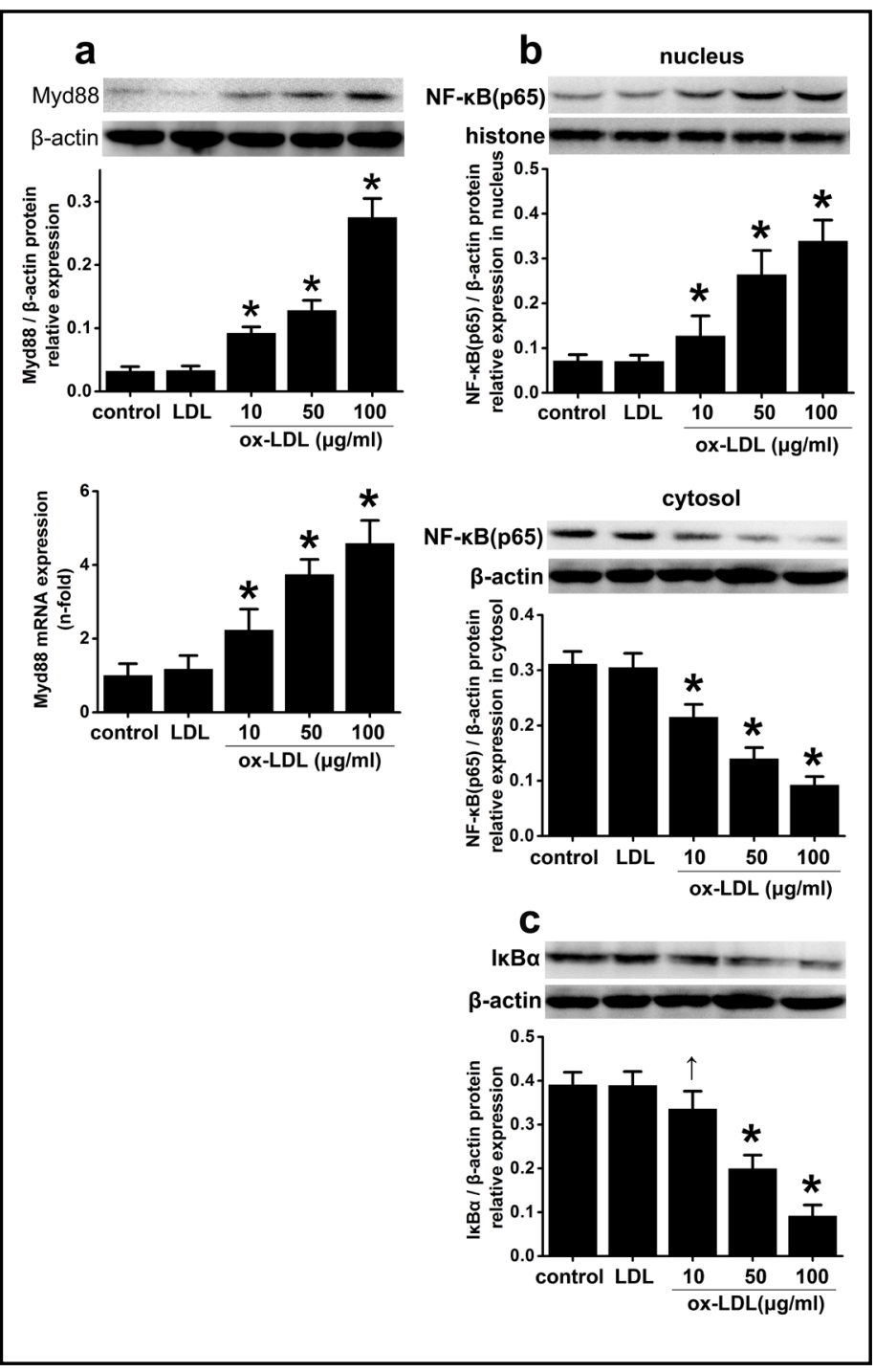

with the NF- $\mathrm{KB}$ inhibitor PDTC, ERK1/2 inhibitor PD98059, p38MAPK inhibitor SB203580 and JNK1/2 inhibitor SP600125 for $1 \mathrm{~h}$, and then stimulated by ox-LDL $(100 \mu \mathrm{g} / \mathrm{mL})$ for 6 or 24 h. As shown in Fig. $6 a$ and b, all inhibitors partly, but significantly decreased ox-LDL-induced expression of MCP-1, TNF- $\beta$ and IL-6, both at mRNA and protein levels in HMC- 1 cells, suggesting that inhibition of NF- $\mathrm{KB}$ and MAPKs effectively suppresses an ox-LDL-induced inflammatory response in $\mathrm{HMC}-1$ cells.

\section{Discussion}

Atherosclerosis is a long-lasting and multi-pathogenic process in the inner and middle wall of arteries, and inflammatory processes in atherosclerotic plaques have been implicated in the progression of clinical atherosclero-thrombotic syndromes. Inflammatory responses, especially oxidative stress, accelerate the accumulation and modification of lipids in atherosclerotic plaques $[3,28]$. Ox-LDL but not LDL has been described as potential promoter of vascular inflammatory responses during atherosclerosis. It stimulates macrophages, endothelial cells, VSMCs and other inflammatory cells to express pro-inflammatory cytokines and display chemotaxis, which induces movement of inflammatory cells into these plaques [12]. 
Fig. 4. Effect of ox-LDL on phosphorylation of extp38 mitogen-activated protein kinase (p38MAPK) and c-Jun N-terninal kinase (JNK). Western-blot analysis of total and phosphorylated protein levels of ERK1/2 (a), p38MARK (b) and JNK (c) in HMC-1 cells incubated with ox-LDL $(10,50$ and $100 \mu \mathrm{g} / \mathrm{mL})$ or native LDL ( $50 \mu \mathrm{g} / \mathrm{mL}$ ) for $30 \mathrm{~min}$. Total MAPKs was used to be the internal control. Gray levels were normalized against those of the corresponding total MAPKs and results were expressed as relative to control. Data are mean \pm S.E.M. of three independent experiments. ${ }^{*} P<0.05$ vs control. racellular signal-regulated kinase $1 / 2$ (ERK1/2),

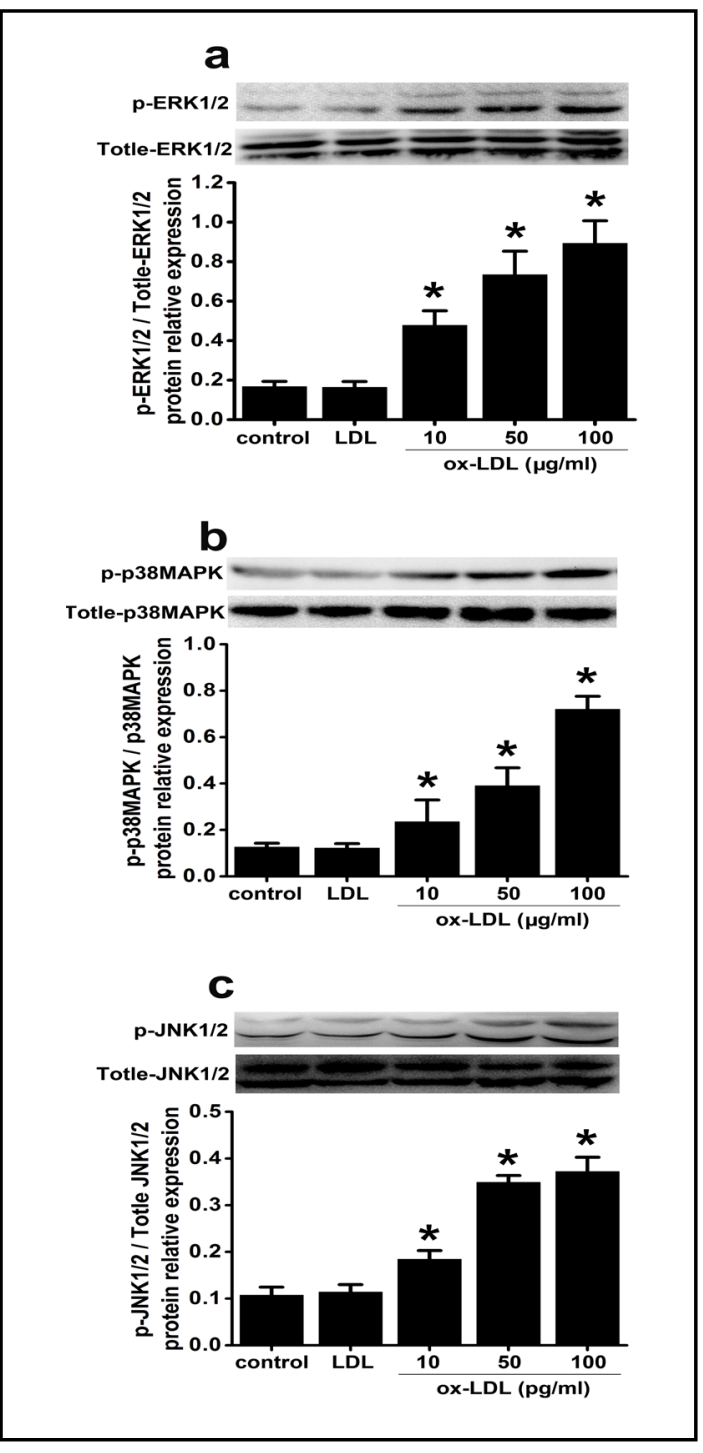

Recently, mast cells and inflammation have been implicated in the development of instable plaques that can rupture and cause thromboses. Growing evidence reveals that mast cells can infiltrate the rupture-prone shoulder region of coronary atheromas and even accumulate during coronary spasms [29]. As compared with normal regions, carotid artery atheromas show marked accumulation of mast cells, and an increased numbers of degranulated mast cells can cause increased matrix metalloproteinase activity in the shoulder of atherosclerotic plaques [30, 31]. Furthermore, the $\mathrm{ldlr}^{-/-} \mathrm{Kit}^{\mathrm{W}-\mathrm{sh} / \mathrm{W}-\mathrm{sh}}$ mice that have dysfunctional mast cells that secrete less proinflammatory cytokines compared with wildtype mice, showed decreased atherosclerosis [32]. Consequently, we focused on the relationship between ox-LDL and inflammation in mast cells. Ox-LDL time- and dose-dependently increased the expression of MCP-1, TNF- $\alpha$ and IL-6 in cultured mast cells, but native LDL had no effects.

Toll-like receptors, especially TLR4, plays an important role in various chronic inflammatory diseases, such as atherosclerosis, diabetes mellitus and hypertension by regulating innate immunity and triggering inflammatory responses [33]. Recently, a growing number of labs have reported increased expression of TLR4 in atherosclerotic plaques both in human and in animal models $[19,20]$. Moreover, atherosclerotic plaques were smaller in TLR4knockout ApoE $\%$ compared to TLR4 suffici ent ApoE $/$ mice [34]. Therefore, TLR4 might contribute to the progression of atherosclerosis. Furthermore, ox-LDL increased mRNA and protein levels of TLR4 in U937 promonocytic leukemia cells and macrophages $[35,36]$. We 


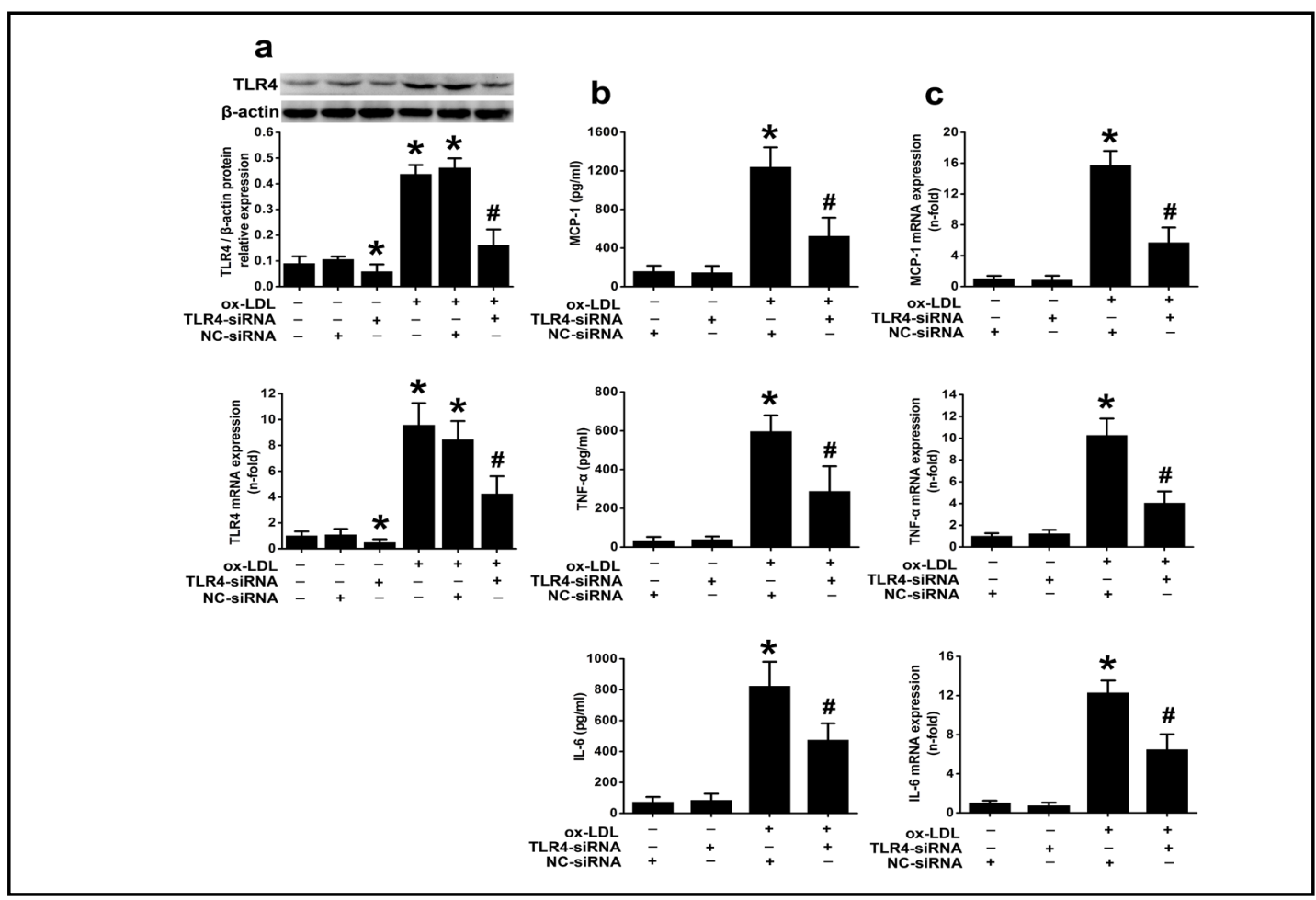

Fig. 5. Effect of TLR4 silencing on ox-LDL-upregulated MCP-1, TNF- $\alpha$ and IL-6 levels. (a) HMCs were transfected with TLR4 or negative control siRNA, then incubated with ox-LDL ( $100 \mu \mathrm{g} / \mathrm{mL})$ for 6 or $24 \mathrm{~h}$. Quantitative real-time PCR and Western blot analysis were used to measure the validation of the silencing of TLR4, respectively. Normalization was to GAPDH mRNA level in quantitative real-time PCR, and $\beta$-actin protein level in the Western-blot. (b) HMC-1 cells were transfected with TLR4-specific or negative control siRNA, then incubated with ox-LDL $(100 \mu \mathrm{g} / \mathrm{mL})$ for $24 \mathrm{~h}$, followed by measurement of protein levels of MCP-1, TNF- $\alpha$ and IL- 6 by ELISA. (c) HMC-1 cells were transfected with TLR4-specific or negative control siRNA, then incubated with ox-LDL (100 $\mathrm{g} / \mathrm{mL})$ for $6 \mathrm{~h}$, and the mRNA levels of MCP-1, TNF- $\alpha$ and IL- 6 were measured by quantitative real-time PCR. Data are mean \pm S.E.M. of 3 independent experiments. ${ }^{*} P<0.05$ vs control; ${ }^{\#} P<0.05$ vs ox-LDL.

found that ox-LDL increased the expression of TLR4 in cultured mast cells, accompanied by the induction of inflammatory cytokine. Using the TLR4-specific siRNA to silence the TLR4 gene, decreased the secretion of MCP-1, TNF- $\alpha$ and IL-6, indicating that TLR4 might be a key regulator of ox-LDL-induced inflammatory responses in cultured mast cells. However, oxLDL reportedly inhibits TLR4-signaling and suppressed the activity of NF- $\kappa B$ in LPS-stimulated macrophages, which is in contrast to our results [37,38]. It is possible that the different cell type and possible differences in the level of LDL-oxidation contributed to these differing results.

Recently several studies focused on entotoxin contamination as a cause of false positive results, in reports about the cytokine function of some "pro-inflammatory proteins", especially C-reactive protein (CRP), heat-shock proteins (HSPs), and high mobility group box 1 (HMGB-1), which are also the ligands of TLR4 [39, 40]. Indeed, endotoxin contamination is very common during sample preparation, including ox-LDL preparation, and however, LPS levels of the previous studies were much higher than the one in our experiments, which was below $0.01 \mathrm{ng} / \mathrm{mL}$. Incubating the HMC-1 cells with $0.01 \mathrm{ng} / \mathrm{mL}$ LPS for $24 \mathrm{~h}$, did not result in a change in pro-inflammatory cytokine secretion, nor in TLR4 expression, indicating that this LPS dose is too low to cause a change in cytokine function and it was indeed ox-LDL, not endotoxin contamination, that induced TLR4-mediated inflammatory responses in HMC-1 cells. 
Fig. 6. Effect of inhibitors on the production of inflammatory mediators. HMC-1 cells were pretreated with NF- $\kappa$ B inhibitor PDTC (10 $\mu \mathrm{mol} / \mathrm{L}), \mathrm{ERK} 1 / 2$ inhibitor PD98059 (30 $\mu \mathrm{mol} / \mathrm{L})$, p38 MAPK inhibitor SB203580 (20 $\mu \mathrm{mol} / \mathrm{L})$ and JNK inhibitor, SP600125 (25 $\mathrm{mol} / \mathrm{L})$ for 1 $h$, then incubated with ox-LDL 100 $\mu \mathrm{g} / \mathrm{mL}$ ) for 6 or $24 \mathrm{~h}$. (a) ELISA detection of protein levels of MCP-1, TNF- $\alpha$ and IL- 6 and (b) quantitative real-time PCR analysis of mRNA levels of MCP-1, TNF- $\alpha$ and IL-6. Normalization was to GAPDH mRNA level. Data are mean \pm S.E.M. of 3 independent experiments. ${ }^{*} P<0.05$ vs control; ${ }^{\#} P<0.05$ vs ox-LDL.

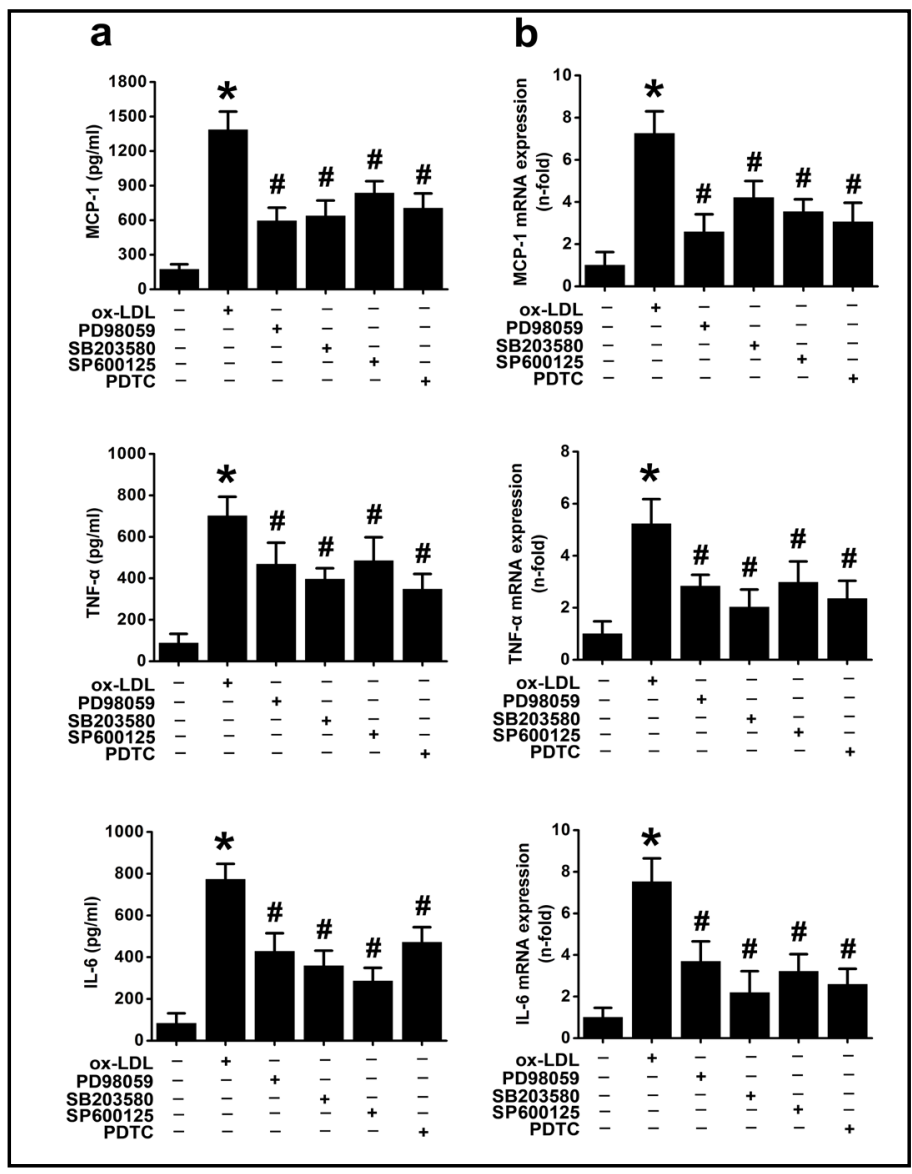

MAPKs, including ERK1/2,JNK1/2 and p38MAPK, arean important group of downstream of mediators in Myd88-dependent TLR4-signaling, and play a critical role in regulating the inflammatory responses, proliferation and apoptosis in various cell types. Ox-LDL can enhance the phosphorylation of p38MAPK and induce nuclear translocation of NF- $\kappa B(p 65)$ in cultured VSMCs [41]. Ox-LDL time- and dose-dependently induced ERK1/2 phosphorylation in human mesangial cells [42]. Additionally, phosphorylation of JNK was markedly increased in ox-LDL-induced VSMCs [43]. Thus, ox-LDL was shown to induce phosphorylation of MAPKs in various cell types. We found that ox-LDL could markedly enhanced phosphorylation of p38MAPK, ERK and JNK. Pretreatment of HMC-1 cells with their respective inhibitors significantly attenuated ox-LDL-induced expression of the inflammatory cytokines in these cells. Therefore, the MAPKs pathway, as a key downstream pathway in Myd88-dependent TLR4mediated signaling, was partly responsible for the ox-LDL-induced inflammatory response in cultured mast cells.

Although we investigated only HMC-1 cells, the results might suggest some molecular mechanisms of the pro-inflammatory effects of ox-LDL with a wider range and highlights the relationship between ox-LDL induced inflammation and activity of TLR4.

In conclusion, we show a novel pathobiological link between ox-LDL stimulation and mast cells in atherosclerosis. Indeed, ox-LDL accumulates in the atherosclerotic regions of arterial intima and medium, where mast cells infiltrate. Ox-LDL may trigger the expression of pro-inflammatory chemotaxis and cytokines by mast cells, which in turn accelerates the atherosclerotic process by increasing the survival, activation and accumulation of other inflammatory cells within atherosclerotic plaques. Here, we found that ox-LDL markedly increased the secretion of MCP-1, TNF- $\alpha$ and IL- 6 inflammatory factors and expression of TLR4 in cultured HMC-1 cells. Moreover, the levels of nuclear NF- $\kappa B$ (p65) and phosphorylated of ERK1/2, p38MAPK and JNK1/2 were significantly upregulated in ox-LDL-stimulated HMC-1 cells. SiRNA inhibition of TLR4 reduced the ox-LDL-induced the expression of inflammatory 
mediators. Finally, pretreatment with inhibitors of ERK1/2, p38MAPK, JNK1/2 and NF- $\kappa B$ (p65) significantly attenuated the ox-LDL-induced inflammatory response in mast cells. OxLDL may stimulate mast cells to secrete inflammatory cytokines in vivo, which might depend in part on TLR4-mediated Myd88-dependent signaling through NF- $\kappa B$. These findings provide further insight into the potential role of TLR4-dependent signaling in regulating inflammatory events in atherosclerosis.

\section{Acknowledgments}

This study was supported by National Science Foundation of China [NSFC 81070219 to Xiao-lin Niu and NSFC 30900617 to Deng-feng Gao]. The authors declare that they have no conflict of interest.

\section{References}

$>1$ Wong BW, Meredith A, Lin D, McManus BM: The biological role of inflammation in atherosclerosis. Can J Cardiol 2012;28:631-641.

$\checkmark 2$ Insull WJ: The pathology of atherosclerosis: plaque development and plaque responses to medical treatment. Am J Med 2009;122:S3-S14. Libby P: Inflammation in atherosclerosis. Arterioscler Thromb Vasc Biol 2012;32:2045-2051. Hansson GK, Hermansson A: The immune system in atherosclerosis. Nat Immunol 2011;12:204-212. Shalhoub J, Falck-Hansen MA, Davies AH, Monaco C: Innate immunity and monocyte-macrophage activation in atherosclerosis. J Inflamm (Lond) 2011;8:9.

-6 Hartvigsen K, Chou MY, Hansen LF, Shaw PX, Tsimikas S, Binder CJ, Witztum JL: The role of innate immunity in atherogenesis. J Lipid Res 2009;50:S388-S393.

7 Hoogeveen RC, Morrison A, Boerwinkle E, Miles JS, Rhodes CE, Sharrett AR, Ballantyne CM: Plasma mcp-1 level and risk for peripheral arterial disease and incident coronary heart disease: atherosclerosis risk in communities study. Atherosclerosis 2005;183:301-307.

8 Sbarsi I, Falcone C, Boiocchi C, Campo I, Zorzetto M, De Silvestri A, Cuccia M: Inflammation and atherosclerosis: the role of tnf and tnf receptors polymorphisms in coronary artery disease. Int J Immunopathol Pharmacol 2007;20:145-154.

-9 Yudkin JS, Kumari M, Humphries SE, Mohamed-Ali V: Inflammation, obesity, stress and coronary heart disease: is interleukin-6 the link? Atherosclerosis 2000;148:209-214.

10 Steinberg D, Witztum JL: Oxidized low-density lipoprotein and atherosclerosis. Arterioscler Thromb Vasc Biol 2010;30:2311-2316.

11 Fraley AE, Tsimikas S: Clinical applications of circulating oxidized low-density lipoprotein biomarkers in cardiovascular disease. Curr Opin Lipidol 2006;17:502-509.

$>12$ Libby P: Inflammation in atherosclerosis. Nature 2002;420:868-874.

13 Huang Y, Hu Y, Mai W, Cai X, Song Y, Wu Y, Dong Y, Huang H, He Z, Li W, Yang Y, Rao S: Plasma oxidized low-density lipoprotein is an independent risk factor in young patients with coronary artery disease. Dis Markers 2011;31:295-301.

14 Wallenfeldt K, Fagerberg B, Wikstrand J, Hulthe J: Oxidized low-density lipoprotein in plasma is a prognostic marker of subclinical atherosclerosis development in clinically healthy men. J Intern Med 2004;256:413-420.

15 Masuda T, Deng X, Tamai R: Mouse macrophages primed with alendronate down-regulate monocyte chemoattractant protein-1 (mcp-1) and macrophage inflammatory protein-1alpha (mip-1alpha) production in response to toll-like receptor (tlr) 2 and tlr4 agonist via smad3 activation. Int Immunopharmacol 2009;9:1115-1121.

16 Ji Y, Liu J, Wang Z, Li Z: Ppargamma agonist rosiglitazone ameliorates lps-induced inflammation in vascular smooth muscle cells via the tlr4/trif/irf3/ip-10 signaling pathway. Cytokine 2011;55:409-419.

17 Wang W, Deng M, Liu X, Ai W, Tang Q, Hu J: Tlr4 activation induces nontolerant inflammatory response in endothelial cells. Inflammation 2011;34:509-518.

18 Erridge C: Endogenous ligands of tlr2 and tlr4: agonists or assistants? J Leukoc Biol 2010;87:989-999. 
19 Xu XH, Shah PK, Faure E, Equils O, Thomas L, Fishbein MC, Luthringer D, Xu XP, Rajavashisth TB, Yano J, Kaul S, Arditi M: Toll-like receptor-4 is expressed by macrophages in murine and human lipid-rich atherosclerotic plaques and upregulated by oxidized ldl. Circulation 2001;104:3103-3108.

20 Edfeldt K, Swedenborg J, Hansson GK, Yan ZQ: Expression of toll-like receptors in human atherosclerotic lesions: a possible pathway for plaque activation. Circulation 2002;105:1158-1161.

-21 Bhaskar S, Shalini V, Helen A: Quercetin regulates oxidized ldl induced inflammatory changes in human pbmcs by modulating the tlr-nf-kappab signaling pathway. Immunobiology 2011;216:367-373. Kalesnikoff J, Galli SJ: New developments in mast cell biology. Nat Immunol 2008;9:1215-1223.

23 Libby P, Shi GP: Mast cells as mediators and modulators of atherogenesis. Circulation 2007;115:24712473.

24 Laird MH, Rhee SH, Perkins DJ, Medvedev AE, Piao W, Fenton MJ, Vogel SN: Tlr4/myd88/pi3k interactions regulate tlr4 signaling. J Leukoc Biol 2009;85:966-977.

25 Baker RG, Hayden MS, Ghosh S: Nf-kappab, inflammation, and metabolic disease. Cell Metab 2011;13:1122.

-26 Theoharides TC, Kempuraj D, Tagen M, Conti P, Kalogeromitros D: Differential release of mast cell mediators and the pathogenesis of inflammation. Immunol Rev 2007;217:65-78.

27 Tam SY, Tsai M, Yamaguchi M, Yano K, Butterfield JH, Galli SJ: Expression of functional trka receptor tyrosine kinase in the hmc-1 human mast cell line and in human mast cells. Blood 1997;90:1807-1820.

28 Peluso I, Morabito G, Urban L, Ioannone F, Serafini M: Oxidative stress in atherosclerosis development: the central role of ldl and oxidative burst. Endocr Metab Immune Disord Drug Targets 2012;12:351-360.

29 Kelley JL, Chi DS, Abou-Auda W, Smith JK, Krishnaswamy G: The molecular role of mast cells in atherosclerotic cardiovascular disease. Mol Med Today 2000;6:304-308.

-30 Jeziorska M, McCollum C, Woolley DE: Mast cell distribution, activation, and phenotype in atherosclerotic lesions of human carotid arteries. J Pathol 1997;182:115-122.

-31 Johnson JL, Jackson CL, Angelini GD, George SJ: Activation of matrix-degrading metalloproteinases by mast cell proteases in atherosclerotic plaques. Arterioscler Thromb Vasc Biol 1998;18:1707-1715.

32 Sun J, Sukhova GK, Wolters PJ, Yang M, Kitamoto S, Libby P, MacFarlane LA, Mallen-St CJ, Shi GP: Mast cells promote atherosclerosis by releasing proinflammatory cytokines. Nat Med 2007;13:719-724.

33 Michelsen KS, Doherty TM, Shah PK, Arditi M: Tlr signaling: an emerging bridge from innate immunity to atherogenesis. J Immunol 2004;173:5901-5907.

-34 Michelsen KS, Wong MH, Shah PK, Zhang W, Yano J, Doherty TM, Akira S, Rajavashisth TB, Arditi M: Lack of toll-like receptor 4 or myeloid differentiation factor 88 reduces atherosclerosis and alters plaque phenotype in mice deficient in apolipoprotein e. Proc Natl Acad Sci U S A 2004;101:10679-10684.

-35 Geng H, Wang A, Rong G, Zhu B, Deng Y, Chen J, Zhong R: The effects of ox-ldl in human atherosclerosis may be mediated in part via the toll-like receptor 4 pathway. Mol Cell Biochem 2010;342:201-206.

36 Yu M, Kang X, Xue H, Yin H: Toll-like receptor 4 is up-regulated by mtor activation during thp-1 macrophage foam cells formation. Acta Biochim Biophys Sin (Shanghai) 2011;43:940-947.

-37 Bzowska M, Nogiec A, Skrzeczynska-Moncznik J, Mickowska B, Guzik K, Pryjma J: Oxidized ldls inhibit tlr-induced il-10 production by monocytes: a new aspect of pathogen-accelerated atherosclerosis. Inflammation 2012;35:1567-1584.

-38 Ohlsson BG, Englund MC, Karlsson AL, Knutsen E, Erixon C, Skribeck H, Liu Y, Bondjers G, Wiklund O: Oxidized low density lipoprotein inhibits lipopolysaccharide-induced binding of nuclear factor-kappab to dna and the subsequent expression of tumor necrosis factor-alpha and interleukin-1beta in macrophages. J Clin Invest 1996;98:78-89.

-39 Pepys MB, Hawkins PN, Kahan MC, Tennent GA, Gallimore JR, Graham D, Sabin CA, Zychlinsky A, de Diego J: Proinflammatory effects of bacterial recombinant human c-reactive protein are caused by contamination with bacterial products, not by c-reactive protein itself. Circ Res 2005;97:e97-e103.

40 Tsan MF: Heat shock proteins and high mobility group box 1 protein lack cytokine function. J Leukoc Biol 2011;89:847-853.

41 Zhong Y, Liu T, Guo Z: Curcumin inhibits ox-ldl-induced mcp-1 expression by suppressing the p38mapk and nf-kappab pathways in rat vascular smooth muscle cells. Inflamm Res 2012;61:61-67.

-42 Hong HK, Song CY, Kim BC, Lee HS: Erk contributes to the effects of smad signaling on oxidized ldl-induced pai-1 expression in human mesangial cells. Transl Res 2006;148:171-179.

43 Sun Y, Chen X: Ox-ldl-induced lox-1 expression in vascular smooth muscle cells: role of reactive oxygen species. Fundam Clin Pharmacol 2011;25:572-579. 